\title{
Features of sensitization and quality of life of patients with allergic rhinitis: A study in North Viet Nam
}

\author{
Andrei Ivanovich Kryukov ${ }^{1,2}{ }^{\circledR}$, Galina Petrovna Bondareva ${ }^{3}$, Thi Phuong Thao Nguyen ${ }^{2, *(\odot) ~}$
}

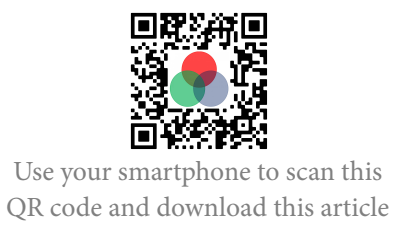

${ }^{1}$ L.I. Sverzhevskiy Research and Clinical Institute of Otorhinolaryngology, Moscow Healthcare Department,

Moscow, Russia

${ }^{2}$ Department of Otorhinolaryngology, Medical Faculty, N.I. Pirogov Russian National Research Medical University, Ministry of Health of the Russian Federation, Moscow, Russia

${ }^{3} \mathrm{NRC}$ Institute of Immunology FMBA of Russia, Moscow, Russia

\section{Correspondence}

Thi Phuong Thao Nguyen, Department of Otorhinolaryngology, Medical Faculty, N.I. Pirogov Russian National Research Medical University, Ministry of Health of the Russian Federation, Moscow, Russia

Email: phuongthao.ent@gmail.com

\section{History}

- Received: Aug 23, 2019

- Accepted: Nov 17, 2019

- Published: Nov 28, 2019

DOI : 10.15419/bmrat.v6i11.576

\section{Check for updates}

Copyright

(๑) Biomedpress. This is an openaccess article distributed under the terms of the Creative Commons Attribution 4.0 International license.

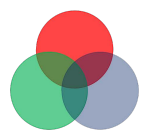

\begin{abstract}
Introduction: Allergic rhinitis (AR) is a critical disease related to otorhinolaryngology, allergology, and pediatrics worldwide due to its high prevalence and treatment costs. This article considers its prevalence based on regional characteristics of sensitization and the quality of patients with allergic rhinitis in North Vietnam. Methods: The study was conducted from June to September 2018 by the Department of Otorhinolaryngology, Thai Nguyen Central General Hospital, Vietnam. A total of 158 patients with symptoms of chronic rhinitis, aged 5-70 years, were examined. All patients with allergic rhinitis were subjected to standard, specific allergological tests, such as skin scarification tests, the determination of specific lgE in the blood, and statistics according to the NOSE scale. All the patients were also examined by otolaryngologists. Results: Among the 158 patients identified with chronic year-round rhinitis, 64 patients were diagnosed with allergic rhinitis. The sensitization to house dust mites and fungi was high. A reduction in quality of life was observed in 70 patients (31\%). Conclusion: Allergic rhinitis can adversely affect every aspect of a patient's life, including sleep quality, mood, and daily activities. Sensitization of patients with allergic rhinitis in Northern Vietnam is similar to those in Asia, with allergy to house dust mites being common.
\end{abstract}

Key words: Allergens, allergic rhinitis, house dust mites, mold, North Vietnam, sensitization

\section{INTRODUCTION}

In recent decades, the prevalence of allergic rhinitis (AR) has increased significantly, making the disease a major contributor to the healthcare burden and morbidity in several countries. Treatment of the established disease is mainly aimed at symptom control and allergen avoidance ${ }^{1}$.

Currently, in the general population, the percentage of residents with seasonal or year-round AR is between 10 to $25 \%$, and in some countries, up to $50 \%$ have signs characteristic of this disease ${ }^{2,3}$. In the United States, the number of patients with AR is $25-30$ million. In England, the prevalence of $\mathrm{AR}$ is $16 \%$, in Denmark- 19\%, and in Germany- 13-17\%. In different regions of the Russian Federation, the prevalence of AR ranges from $12.7-24 \%{ }^{4}$; the prevalence is $23-30 \%$ in Europe, $12-30 \%$ in the USA, $5.5-45.1 \%$ in Latin America, 7.2-54.1\% in Africa, and 9.1-35.7\% in Japan/Korea ${ }^{5}$.

Differences in geography, climate, and urbanization affect the global distribution of aeroallergens and, correspondingly, their sensitization patterns in humans. Different patterns of aeroallergen sensitization have been seen in various parts of the world; the Asian allergome and allergic disease phenotypes are distinct from those in Europe and the United States ${ }^{1}$.
Atopic patients in Europe and the United States are more highly sensitized to animal dander (cat and dog) and pollen than Asians. House dust mites (HDM) are by far the most common aeroallergen implicated in allergic people in Asian countries. The highest rates of HDM sensitization have been reported in Singapore (70 to $>90 \%$ ) and South India (89.7\%); the lowest sensitization rates have been described in North India (7.8\%), Vietnam (9-23\%), and the Philippines $(33-47 \%)^{1}$.

Even though the manifestations of AR are not regarded as a serious illness, they have negative effects on the physical, psychological and social aspects of human life ${ }^{6}$. AR contributes to missed or unproductive time at work and school, problems with sleep, and in affected children, reduced involvement in outdoor activities.

Many studies of quality of life have emphasized that adult patients are disturbed by sleep disturbances and by annoying practical problems, such as the need to blow one's nose and carry handkerchiefs, as well as restrictions on their daily activities. Studies have shown that although younger children show less concern about emotional dysfunction and disturbances in everyday life, they are more concerned about the need to take medicine and wear handkerchiefs ${ }^{7}$. Moreover, their parents seem more worried than the children 
themselves. In addition to poor sleep quality, daytime tiredness and drowsiness are often observed in children ${ }^{7}$.

The assessment of quality of life has become a major area of interest for clinical research. Quality of life (QOL) questionnaires have been developed to assess the effects of clinical management and of reducing the symptoms of chronic diseases on the patient's daily life, and to evaluate the effects of particular methods of treatment on controlling the disease.

The nasal obstruction symptom evaluation (NOSE) scale and QOL questionnaires are brief, valid, reliable, and responsive surveys to measure disturbances in the quality of life specific to nasal obstruction. The NOSE Scale was conducted as part of a parallel prospective multicenter observational clinical study. This multicenter study was commissioned and funded by the American Academy of Otolaryngology-Head and Neck Surgery Foundation, and coordinated under the auspices of its National Center for the Promotion of Research in Otolaryngology ${ }^{8}$. Many recent studies have used the NOSE scale as a primary outcome measure for surgical treatment of nasal obstruction ${ }^{9}$. A study conducted in India (2015) provided further evidence that the quality of life of allergic rhinitis patients was worse than that of non-rhinitis subjects. Indeed, allergic rhinitis impairs the quality of life of persons in different domains ${ }^{7}$.

Our study was conducted to assess the sensitization and quality of life of patients with symptoms of nasal obstruction and characteristics of allergic rhinitis in Northern Vietnam.

\section{MATERIALS AND METHODS}

\section{Materials}

The study was conducted from June to September 2018 by the Department of Otorhinolaryngology, Thai Nguyen Central General Hospital, Vietnam. The field of study included urban and rural areas. An urban area was defined as having a population density (in 2018) from 400 to 3000 people per $\mathrm{km}^{2}$, and a rural area was defined as having a developing modern agricultural production and industrial plants ${ }^{6}$. A total of 556 patients (aged 5 to 70 years) with pathology of ear-nose-throat (ENT) organs were examined, of which 158 patients were identified and diagnosed as having chronic rhinitis (CR).

\section{Methods}

All patients with CR were assessed for complaints of nasal congestion, olfactory disturbance, sneezing, itching (in the nasal cavity and eyes), rhinorrhea, and drainage of mucus along the back wall of the pharynx. In this study, the exclusion criteria were as follows: pregnancy or lactation, acute infectious pathologies, autoimmune diseases, oncopathology, psychosomatic disorders, AIDS, treatment with antihistamines, use of glucocorticosteroids, and use of mast cell stabilizers.

All patients with CR underwent a standard specific and thorough allergological study, which included allergological history, NOSE scale (Table 2), skin scarification tests, and the determination of specific IgE in the blood in response to house dust, pollen, and epidermal allergens (manufactured by NPO Microgen, Russia).

The study was approved by the Medical Ethics Research Committee of Thai Nguyen Central General Hospital, Vietnam. Informed consent was obtained from the patients before any tests or evaluations were conducted.

\section{Allergological history}

The interview questionnaire used was the recently developed questionnaire from the Russian Association of Allergologists and Clinical Immunologists ${ }^{10}$. Additional questions were taken from the Global Allergy and Asthma European Network (GA2LEN) questionnaire ${ }^{11}$. The questionnaire of our study herein included questions mainly about respiratory and allergic symptoms, diagnoses, and smoking habits, such as the below:

- a. Allergic rhinitis (AR): "Do you have nasal allergy, including hay fever?"

- b. AR symptoms lasting 12 months: "Have you been troubled by nasal allergies in the last 12 months?"

- c. "When/what was the frequency of duration of nasal congestion (year, month or season)?"

- d. "What is the reason for AR? (describe exact conditions)"

- e. Definitions of possible risk factors including smoking habits have been described in detail previously. "Are you a smoker?"

- f. "What concomitant diseases (bronchial asthma, nasal polyp, etc.) do you have?"

- g. Patients carry out an anamnesis collection questionnaire with scores (Table 1 ). Patients are evaluated for nasal congestion, rhinorrhea, and olfactory disturbance. The severity of symptoms is noted as points. The presence of 7-9 points indicates a severe course of the disease, 


\begin{tabular}{lll}
\hline Table 1: Symptom scores & Score & Number of patients \\
\hline Nasal Congestion & 3 & 2 \\
\hline Persistent nasal congestion & 1 \\
Periodic nasal congestion & 0 \\
Minor difficulty in nasal breathing & \\
Free nasal breathing & 3 \\
The severity of rhinorrhea & 2 \\
Permanent discharge from the nasal cavity & 1 \\
Periodic discharge from the nasal cavity & 0 \\
Moderate discharge from the nasal cavity & \\
No nasal discharge & 3 \\
Olfactory disturbance & 2 \\
Anosmia & 1 \\
Hyposmia & 0 \\
Intermittent Hyposmia & \\
No dysfunction & \\
Total & \\
\hline & & \\
\hline
\end{tabular}

Table 2: Nasal obstruction symptom evaluation (NOSE) scale

\begin{tabular}{lccccc}
\hline & Not a problem & $\begin{array}{c}\text { Very mild } \\
\text { problem }\end{array}$ & $\begin{array}{c}\text { Moderate } \\
\text { problem }\end{array}$ & $\begin{array}{c}\text { Fairly bad } \\
\text { problem }\end{array}$ & Severe problem \\
\hline Nasal stuffiness & 0 & 1 & 2 & 3 & 4 \\
$\begin{array}{l}\text { Nasal blockage or obstruc- } \\
\text { tion }\end{array}$ & 0 & 1 & 2 & 3 & 4 \\
$\begin{array}{l}\text { Trouble breathing through } \\
\text { my nose }\end{array}$ & 0 & 1 & 2 & 3 & 4 \\
$\begin{array}{l}\text { Trouble sleeping } \\
\begin{array}{l}\text { Unable to get enough air } \\
\text { through my nose during } \\
\text { exercise or exertion }\end{array}\end{array}$ & 0 & 1 & 2 & 3 & 4 \\
\hline
\end{tabular}

4 to 6 points indicates moderate severity of disease, and 0 to 3 points indicates mild course of disease.

\section{NOSE scale}

The NOSE scale is composed of five questions about the severity of nasal obstruction. Each item is evaluated using a Likert scale- from 0 (not a problem) to 4 (severe problem). The data is summarized and then multiplied by 5 for a total final NOSE score ranging between 0 to 100 . A higher NOSE score reflects greater severity of self-reported nasal obstruction. The total NOSE scores were categorized into previously described severity ranges including: mild (range of 5-25), moderate (range of 30-50), severe (range of 55-75), or extreme (range of 80-100) ${ }^{12}$.

\section{Skin scarification tests (SST)}

The skin scarification tests (SST) were performed according to the standards developed by the Russian University of Allergology and Clinical Immunology ${ }^{10}$, using a special disposable lancet with allergens fixed on it. Ten allergen extracts were used and provided by NPO "Microgen" (Russia): house dust, cat, dog, Dermatophagoides pteronyssinus, Dermatophagoides farinae, Alternaria alternata, mixed 
grass, mixed tree, pollen from Atriplex, and pollen from Artemisia. At the same time, tests with histamine $(10 \mathrm{mg} / \mathrm{ml})$ and physiological saline were carried out in a similar way (they were used as positive and negative controls). A positive reaction was recorded if the mean diameter of the wheal was $\geq 5 \mathrm{~mm}$. The wheal was recorded after 15-20 minutes, and the mean wheal diameter was measured by adding the largest diameter and its perpendicular diameter. No subjects had a reaction to the negative control agent, but all subjects had a positive reaction to histamine. The exclusion criteria for participation in the SST was age 15-70 years, with also the above exclusion criteria.

\section{Specific IgE in the blood test}

Specific IgE in the blood was determined for allergens including house dust allergens (house dust mitesD. Pteronysinus, D. Farinae, and Blomia tropicalis), an allergen from cockroaches, hay dust, molds (Aspergillus fumigatus, Alternaria alternata/ tenuis, Cladosporium herbarum, and Penicillium notatum), and food allergens (shrimp, crab, squid, mackerel, sardines, tuna, beef, chicken, egg yolk, and vegetables (celery, mushrooms, onions, or soy)). The measured values could automatically be used to calculate the concentration (in IU/ml) of allergen-specific IgE in each band. The RIDA qLine Allergy test system and the 1-Viet panel (from R-Biopharm AG, Germany) were used with WHO standards. A positive reaction was recorded if specific IgE blood was $\geq 0.7 \mathrm{IU} / \mathrm{ml}$.

\section{Statistical analysis}

All statistical analyses were performed by a professional statistician using Microsoft Excel version 12.0.4518.1014 and SPSS Statistics 20. Descriptive statistics methods were used to evaluate the results. To find the correlative relationship between the traits, the Friedman and Wilcoxon rank correlation methods were used; a p-value $<0.05$ was considered statistically significant. Demographic and exposure data were used as independent variables; these included sex, age, area, and smoking habits. The results were expressed as odds ratios (OR) with 95\% confidence intervals (CI).

\section{RESULTS}

According to the results of our study, among 158 patients with a diagnosis of chronic rhinitis (CR), a total of 64 patients were diagnosed as allergic rhinitis (AR), with an average duration of morbidity of $5.4 \pm$ 1.6 years.
Among the patients with AR, 33 (51.56\%) were men and 31 (48.44\%) were women.

The age distribution of the subjects of AR was: $4.69 \%$ (under the age of 20 years); $50 \%$ (aged 20 to 40 years); $35.93 \%$ (aged 40 to 60 years); and $9.38 \%$ (aged 60 to 70 years). In AR subjects, $70.31 \%$ (45/64) remained in urban districts, and $29.69 \%$ (19/64) in rural districts; furthermore, out of the 64 AR patients, 11 (17.19\%) patients did not live far from industrial factories. $\mathrm{Pa}$ tients living in urban areas were more associated with AR prevalence than in rural areas $(\mathrm{OR}=1.51)$.

A diagnosis of AR was established in 63 (98.4\%) patients, while the symptoms of the disease had yearround manifestations. However, only 1 (1.56\%) patient had seasonal symptoms from May to September. The anamnesis showed that only 1 patient suffered from bronchial asthma. A history of nasal trauma (fracture of the nasal bones) occurred in 1 (1.56\%) patient, operations on ENT organs in 9 (14.06\%) patients, operations on the nasal septum (septoplasty and submucosal resection of the nasal septum) occurred in $6(9.4 \%)$ patients, and tonsillectomy in 3 (4.7\%) patients.

According to the history of patients, vasoconstrictor drugs (Naphazolin, Otrivin, etc.) were often used for long-term in 4 (6.25\%) patients and 21 (32.81\%) patients; all of them were men. Their smoking history ranged from 7 to 17 years, they smoked from 5 cigarettes up to 1 pack per day, and 5 patients were diagnosed with polyps of the middle turbinate. Patients who were smokers had a significant risk of AR incidence $(\mathrm{OR}=1.46)$.

Rhinorrhea was the most prevalent symptom among the participants: $58(90.62 \%)$ patients complained of nasal congestion, $57(89.06 \%)$ had private onset sneezing, 22 (34.38\%) had itching in the nasal cavity, $22(34.38 \%)$ had itchy eyes, $14(21.78 \%)$ had olfactory disturbance, and 45 (70.31\%) experienced continuous discharge from the nasal cavity or drainage of mucus into the nasopharynx. After assessing the severity of the main symptoms according to the score, as Table 3 shows, 19 (29.69\%) patients possessed mild symptoms, 28 (43.75\%) had moderate symptoms, and 17 (26.56\%) had severe symptoms.

Moreover, according to the NOSE scale, the effect of nasal congestion on the quality of life was shown statistically; among the total of 64 patients, the quality of life was mildly affected in $19(29.69 \%)$ patients, moderately affected in $32(50 \%)$ patients, and severely affected in 13 (20.31\%) patients. The quality of life was reduced markedly in patients with severe intermittent allergic rhinitis $(p=0.0012)$. These results shows the consistency between the assessment of the severity of 


\begin{tabular}{lcc}
\hline Table 3: Symptom scores of patients with AR & & \\
\hline Nasal Congestion & Score & Number of patients \\
\hline Persistent nasal congestion & 3 & $10(15,63 \%)$ \\
Periodic nasal congestion & 2 & $12(18,75 \%)$ \\
Minor difficulty in nasal breathing & 1 & $36(56,25 \%)$ \\
Free nasal breathing & 0 & $6(9,37 \%)$ \\
The severity of rhinorrhea & 3 & $17(26,56 \%)$ \\
Permanent discharge from the nasal cavity & 2 & $22(34,38 \%)$ \\
Periodic discharge from the nasal cavity & 1 & $6(9,37 \%)$ \\
Moderate discharge from the nasal cavity & 0 & $19(29,69 \%)$ \\
Nonasal discharge & & \\
Olfactory disturbance & 3 & 0 \\
Anosmia & 2 & $5(7,81 \%)$ \\
Hyposmia & 1 & $9(14,06 \%)$ \\
Intermittent Hyposmia & 0 & $50(78,13 \%)$ \\
No disfunction & & $64(100 \%)$ \\
Total & 2 & \\
\hline
\end{tabular}

symptoms and the effects of the degree of nasal congestion on the quality of life of the patient.

According to the results of skin scarification tests, an isolated sensitization to an allergen from house dust was found in only $3(4.69 \%)$ patients, while sensitization to house dust was combined with mite allergy in $33(51.56 \%)$ patients. Twenty $(31.25 \%)$ patients showed positive reaction to both $D$. pteronyssinus and D. farinae, while 18 (28.13\%) showed only response to only 1 type of mites (D. pteronyssinus or D. farinae). Sensitization to an allergen from cereal herb mix with an allergy to house dust was found in 3 (4.69\%) patients. In the study group of patients, positive scarification tests for pollen and epidermal allergens were rarely detected. Therefore, according to the results of the skin tests, sensitization to epidermal allergens were found in $9(14.1 \%)$ patients; of them, 5 (7.81\%) were allergic to cats, and $4(6.25 \%)$ to dogs. In $5(7.81 \%)$ patients, sensitization to a mixture of trees was revealed, in $3(4.69 \%)$ to a mixture of herbs, in $1(1.56 \%)$ to pollen of Atriplex, and in $1(1.56 \%)$ to pollen of Artemisia.

According to the results of determining the level of specific IgE in the blood, it was shown that the specific IgE prevalence for D. pteronyssinus was $61.1 \%$, for B. tropicalis- $64.06 \%$, and for D. farinae- $56.25 \%$. Additionally, $17.19 \%$ patients were reactive for a mixture of molds (Aspergillus fumigatus, Alternaria alter- nata/tenuis, Cladosporium herbarum, Penicillium notatum). Six (9.37\%) patients were allergic to feathers, $3(4.69 \%)$ - to cat hair, $2(3.13 \%)$ - to dog hair, $1(1.56 \%)$ - to cereal pollen, $2(3.13 \%)$ - to shrimp, 2 (3.13\%)- to cockroaches, and 1 (1.56\%)- to crabs. Other non-bacterial allergens showed negative results (induced no reactions).

Among the 64 patients with AR, only 1 (1.56\%) suffered from bronchial asthma, and $9(14.06 \%)$ were diagnosed with nasal polyps, of which $6(9.37 \%)$ had an increased level of specific IgE in the blood to the mold mixture.

\section{DISCUSSION}

At the ENT department of Thai Nguyen Central General Hospital, Vietnam, we discovered a high prevalence of AR in patient referrals, reaching up to $40.5 \%$ for chronic rhinitis and $11.5 \%$ for ENT pathologies. By comparison, the prevalence of $\mathrm{AR}$ in northern Vietnam was the same, as demonstrated by the results of the research conducted among adult in East Asia $^{13}$. A questionnaire based on telephone interviews in large cities of China for the period 2004-2005 revealed that the prevalence of AR ranged from 9-24\% in South Korea ${ }^{13}$. Moreover, an even lower prevalence rate of AR was found, amounting to $6-10 \%{ }^{14}$. The prevalence of AR in the last decade of the twentieth century is as follows: $12 \%$ in Moscow, $12.7 \%$ in 
the Leningrad region, $15 \%$ in the Bryansk region, $19 \%$ in the Rostov region, $24 \%$ in the Sverdlovsk region, and $21 \%$ in Udmurtia ${ }^{15}$. Additionally, according to a 2001 study conducted on children in the centre of Hanoi, the prevalence of diagnosis of allergic rhinitis in these children was $11 \%{ }^{16}$.

In our study, we noted the prevalence of AR in Vietnam as $70.3 \%$ in urban areas and, in contrast, it was $29.7 \%$ in rural areas. This indicator corresponds with the 2014 study by H.T. Lam, which found that the prevalence of AR in the central/rural areas of Hanoi, versus the capital of Vietnam located in the north of Vietnam, was $30 \%$ and $10 \%$, respectively ${ }^{17}$. An analysis of risk factors confirmed that urban lifestyle poses a risk for AR, with occupational exposure to dust, gases, and vapors ${ }^{18}$.

Our results also demonstrate that the prevalence of AR among men is the same as for women. While men may have more contact with bad habits (smoking, alcohol consumption, etc.), housework is a risk factor for women.

An increased risk of allergic diseases among people exposed to tobacco smoke has been reported ${ }^{19}$. Our study results also confirm that smoking is a risk factor associated with AR. Smoking can increase sensitivity to both perennial indoor allergens and some outdoor allergens ${ }^{20}$. In addition, smoking enhances the nasal response to allergens in patients with AR showing high levels of $\operatorname{IgE}, \operatorname{IgG}_{4}$, and histamine in nasal secretions $^{21}$. Smoking is common in Vietnam because Vietnam is the largest tobacco consumer in the world. In fact, an increase in the number of smokers may be one plausible explanation for the increase in prevalence of AR.

Most patients independently use pills sold without controls in pharmacies in this territory and have not carefully examined their condition. Therefore, it is difficult to diagnose AR as intermittent or persistent, and mild, moderate or severe.

Due to the tropical climate with high humidity and since annual flowering time is not determined, in northern Vietnam the prevalence of house dust mites and molds is high. This sensitization pattern was also demonstrated in adult asthmatics in Singapore and Malaysia $^{22,23}$, and corresponds to the sensitization pattern in preschool children with AR living in urban areas of the Altai Territory, studied from September 2015 to April 2016. In this study, the prevalence of sensitization to $D$. pteronyssinus was $58.4 \%$ and to $D$. farinae was $35.1 \%{ }^{24}$. The rate of mold sensitivity in our study, however, is higher than that of the study of female school children in Thailand, in which only
$1.2 \%$ of the children showed increased sensitivity to mold $^{25}$.

Cross-sensitivity was noted to three types of allergens from ticks of the species D. pteronyssinus, D. farinae, and B. tropicalis. Thus, patients with tick allergies to $D$. pteronyssinus and D. farinae, respectively, had sensitization to B. tropicalis. Allergies to all three allergens were significantly more common among citizens than among rural residents, and were found among patients of the middle age group of 20-45 years old $(\mathrm{p}<0.001)$.

Before treatment, the chronic symptoms of AR of this study were strongly expressed in chronic nasal congestion (90.6\%) and chronic runny nose (70,31\%), and were distributed in both urban and rural areas. For comparison, there are no published data on the prevalence of chronic AR symptoms in Southeast Asia; these symptoms have also rarely been studied in other countries. In a recent European study, prevalence of runny nose was reported as $20 \%$ in the United Kingdom; in Western Sweden the prevalence of nasal congestion was reported as $15 \%$ and chronic runny nose as $13 \%{ }^{17}$.

The results obtained from the present study show a significant relationship between quality of life and severity of disease. Indeed, patients with severe permanent or intermittent disease had a poorer quality of life. These observations are consistent with those from other studies, such as one conducted by Ramona Ungureanu and Dorin Sarafoleanu in 2012, which showed that patients with a more severe type of AR have a poorer quality of life ${ }^{26}$.

\section{CONCLUSION}

The results show that among patients with chronic year-round rhinitis in the North Vietnam region, $40 \%$ of them had AR, with predominant sensitization to house dust mites and molds. Sensitization was three times more common in urban residents than rural residents.

Given the significant effects of these symptoms of AR on the patients' quality of life, making an early diagnosis of the disease is the first step to overcoming or managing the disease. The findings of our study can help shape the next steps of treatment for AR, such as reducing environmental allergens and taking measures to prevent the incidence of concomitant diseases, such as asthma and sinusitis, with higher efficiency.

\section{ABBREVIATIONS}

AR: Allergic rhinitis

CR: Chronic rhinitis 
HDM: House dust mites

NOSE: Nasal obstruction symptom evaluation

ARIA: Allergic Rhinitis Impact on Asthma

QoL: Quality of life

ENT: Ear, Nose, and Throat

SST: Scarification skin tests

\section{COMPETING INTERESTS}

The authors declare that they have no conflicts of interest.

\section{AUTHORS' CONTRIBUTIONS}

AI, GP and NTPT collected the data. NTPT conducted analysis and interpretation of data. NTPT drafted the first version. All authors edited the first draft. All authors reviewed, commented and approved the final draft.

\section{ACKNOWLEDGMENTS}

This work was supported by the Thai Nguyen Central General Hospital, Vietnam, no under grant.

\section{REFERENCES}

1. Tham EH, Lee AJ, Bever HV. Aeroallergen sensitization and allergic disease phenotypes in Asia. Asian Pac J Allergy Immunol. 2016;34(3):181-9. PMID: 27543739.

2. Kryukov Al, Turovsky AB, Bondareva GP, Semkin OV. Principles of treatment of allergic rhinitis. Meditsinskiysovet. 2013;7:427.

3. Nikiforova GN, Volkova KB, Svistushkin VM. Place and importance of modern antihistamines in the treatment of allergic rhinitis. Russian Allergology Journal. 2015;23:1395-8.

4. Kurbacheva OM, Polner SA, Smirnov DS. Allergic rhinitis. Eternal problem and its modern solution. Meditsinskiysovet. 2015;3:84-94.

5. Prosekova EV, Turyanskaya Al, Netesova SY, Sabynich VA. Effectiveness of antihistamine in the therapy of allergic persistent rhinitis in younger pupils: clinical and immunological aspects. Russian Allergology Journal. 2016;1:57-62.

6. Okubo K, Kurono Y, Ichimura K, Enomoto T, Okamoto $Y$, Kawauchi $\mathrm{H}$, et al. Japanese guidelines for allergic rhinitis 2017. Allergol Int. 2017;66(2):205-19. PMID: 28214137. Available from: 10.1016/j.alit.2016.11.001.

7. Chauhan G, Khokhar C. Quality of Life in Allergic Rhinitis Patients. The International Journal of Indian Psychology. 2015;2(2):114-22.

8. Stewart MG, Witsell DL, Smith TL, Weaver EM, Yueh B, Hannley MT. Development and validation of the Nasal Obstruction Symptom Evaluation (NOSE) scale. Otolaryngol Head Neck Surg. 2004;130(2):157-63. PMID: 14990910. Available from: 10.1016/j.otohns.2003.09.016.

9. Lipan MJ, Most SP. Development of a severity classification system for subjective nasal obstruction. JAMA Facial Plast Surg. 2013;15(5):358-61. PMID: 23846399. Available from: 10.1001/jamafacial.2013.344.

10. Federal clinical guidelines for the diagnosis of allergic diseases Moscow, 2015; 1-28; 2015. Available from: http://nrcii.ru/ docs/Klinicheskie_rekomendacii_po_diagnostike_AZ.pdf.
11. Bousquet J, Burney PG, Zuberbier T, Cauwenberge PV, Akdis CA, Bindslev-Jensen C, et al. GA2LEN (Global Allergy and Asthma European Network) addresses the allergy and asthma 'epidemic'. Allergy. 2009;64(7):969-77. PMID: 19392994. Available from: 10.1111/j.1398-9995.2009.02059.x.

12. Gerecci D, Casanueva FJ, Mace JC, Annen A, et al. Nasal Obstruction Symptom Evaluation Score Outcomes AfterSeptorhinoplasty. Laryngoscope. 2018;00:1-6. PMID: 30575041.

13. Zhang L, Han D, Huang D, Wu Y, Dong Z, Xu G, et al. Prevalence of self-reported allergic rhinitis in eleven major cities in china. Int Arch Allergy Immunol. 2009;149(1):47-57. PMID: 19033732. Available from: 10.1159/000176306.

14. Park HS, Choi GS, Cho JS, Kim YY. Epidemiology and current status of allergic rhinitis, asthma, and associated allergic diseases in Korea: ARIA Asia-Pacific workshop report. Asian Pac J Allergy Immunol. 2009;27(2-3):167-71. PMID: 19839504.

15. Lopatin AS, Chuchueva ND. Epidemiology of allergic rhinitis in Russia and world. Russian Allergology Journal. 2013;2:3-10.

16. Nga NN, Chai SK, Bihn TT, Redding G, Takaro T, Checkoway H, et al. ISAAC-based asthma and atopic symptoms among $\mathrm{Ha}$ Noi school children. Pediatr Allergy Immunol. 2003;14(4):2729. PMID: 12911504. Available from: 10.1034/j.1399-3038.2003. 00043.x.

17. Lâm HT, Tng NVT, Ekerljung L, Rönmark E, Lundbäck B. Allergic rhinitis in northern vietnam: increased risk of urban living according to a large population survey. Clin Transl Allergy. 2011;1(1):7. PMID: 22410330. Available from: 10.1186/20457022-1-7.

18. Eriksson J, Ekerljung L, Pullerits T, Holmberg K, Rönmark E, Lötvall J, et al. Prevalence of chronic nasal symptoms in West Sweden: risk factors and relation to self-reported allergic rhinitis and lower respiratory symptoms. Int Arch Allergy Immunol. 2011;154(2):155-63. PMID: 20733324. Available from: $10.1159 / 000320230$.

19. Saulyte J, Regueira C, Montes-Martínez A, Khudyakov $P_{,}$ Takkouche B. Active or passive exposure to tobacco smoking and allergic rhinitis, allergic dermatitis, and food allergy in adults and children: a systematic review and meta-analysis. PLoS Med. 2014;11(3):e1001611. PMID: 24618794. Available from: 10.1371/journal.pmed.1001611.

20. Lannerö $E$, Wickman $M$, van Hage $M$, Bergström A, Pershagen $G$, Nordvall L. Exposure to environmental tobacco smoke and sensitisation in children. Thorax. 2008;63(2):172-6. PMID: 18089631. Available from: 10.1136/thx.2007.079053.

21. Diaz-Sanchez D, Rumold R, Gong H. Challenge with environmental tobacco smoke exacerbates allergic airway disease in human beings. J Allergy Clin Immunol. 2006;118(2):441-6. PMID: 16890770. Available from: 10.1016/j.jaci.2006.04.047.

22. Chew FT, Lim SH, Goh DY, Lee BW. Sensitization to local dustmite fauna in Singapore. Allergy. 1999;54(11):1150-9. PMID: 10604550. Available from: 10.1034/j.1398-9995.1999.00050.x.

23. Sam CK, Soon SC, Liam CK, Padmaja K, Cheng HM. An investigation of aeroallergens affecting urban Malaysian asthmatics. Asian Pac J Allergy Immunol. 1998;16(1):17-20. PMID: 9681124.

24. Shakhova NV, Kamaltynova EM, Lobanov YF, Ardatova TS. Allergic rhinitis in preschool children living in urban conditions of the Altai Territory: a population-based simultaneous study. Voprosy sovremennoy pediatrii. 2017;17(3):236-243. Available from: 10.15690/vsp.v17i3.1893.

25. Prasarnphanich T, Sindhurat S. Sensitization to common indoor allergens and its association with allergic diseases in Thai female high-school students. Pediatr Allergy Immunol. 2005;16(5):402-7. PMID: 16101932. Available from: 10.1111/j. 1399-3038.2005.00297.x.

26. Ungureanu R. DorinSarafoleanu. Quality of life in patients with chronic hypertrophic rhinitis after $\mathrm{CO} 2$ laser turbinoplasty. Romanian Journal of Rhinology. 2012;2(8):209-16. 